\title{
On the multiple time scales of variability in the Northeast Pacific Ocean
}

\author{
R. Tokmakian \\ Department of Oceanography, Naval Postgraduate School, Monterey, California, USA
}

Received: 10 January 2009 - Published in Ocean Sci. Discuss.: 24 February 2009

Revised: 24 September 2009 - Accepted: 1 October 2009 - Published: 17 November 2009

\begin{abstract}
The spatial and temporal sea surface height energy distribution of the Northeast Pacific Ocean is described and discussed. Using an altimetric data set covering 15 years (1993-2007), the energy within the 3-9 month band is primarily located within $10^{\circ}$ of the coast. In the Gulf of Alaska, this energy signal is on the shelf, while further south, west of the California/Oregon coast, the significant energy in this band is west of the shelf break. In both cases, it is primarily forced by the local wind. Within the $2-3$ year band, the signal reflects energy generated by local changes to the wind stress from large atmospheric shifts indicated by the Pacific North American Index and by advective or propagating processes related to El Niño-Southern Oscillation. Over the two 4-6 year periods within this data set, the change is primarily due to the large scale shift in atmospheric systems north of about $30^{\circ} \mathrm{N}$ which also affect changes in current strengths. Based on the distribution of the energy signal and its variability, a set of three winter-time indices are suggested to characterize the distinct differences in the SSH anomalies in these areas.
\end{abstract}

\section{Introduction}

The ocean's circulation patterns contain variability on a wide range of scales. This paper describes the variability of the circulation patterns of the Northeast Pacific Ocean. Using the information from the spectral energy decomposition of the sea surface height (SSH) anomaly signal, a set of SSH based indices is suggested as useful tools to monitor the changes in the flow patterns of the Northeast Pacific that may impact the non-physical aspects of ecosystems of the area.

The motivation and the Northeast Pacific circulation's variability, as seen in prior papers, is first described briefly

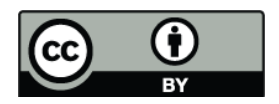

Correspondence to: $\mathrm{R}$. Tokmakian (rtt@nps.edu) in the following sections of the introduction. It is followed by a description of the region of interest and its sub-regions (see Sect. 2.1) and a description of the analysis methods used for this paper. The third and fourth sections describe the signal in its decomposition and the variability of specific bands of variability, the reasons for the variability, and any relationships between sub-regions. Finally, the last section concludes by providing a set of indices based on the distribution of the SSH spectral energy in time and space over the region that characterize an area's variability.

\subsection{Motivation}

The objective for this research is to understand the spatial and temporal distribution of the variability in the Northeast Pacific and how the information can contribute to an understanding of the predictability of the ocean's circulation. The changes in local energy relate to both local and remotely forced events. Both of these event types will be examined in this paper. Analysis of ocean variability at inter-annual to decadal periods using satellite data is now feasible with the collection of relatively long time series (e.g. SSH and sea surface temperature: SST) of data that are spatially dense. This paper expands on previous research by exploring the multiscale variability of the SSH signal in the Northeast Pacific over about a decade.

\subsection{Background}

The North Pacific Current flows eastward as a broad current centered around $45^{\circ} \mathrm{N}$ and then splits into the northward flowing Alaskan Current and the southward flowing California Current. The two currents are out of phase with each other (Chelton and Davis, 1982; Douglass et al., 2006). The southward flowing, broad California Coastal Current has been studied extensively including its seasonal variability. On temporal scales longer than seasonal, previous analyses have focused on large-scale atmospheric influences on the

Published by Copernicus Publications on behalf of the European Geosciences Union. 
circulation. For example, LLuch-Belda et al. (2003) examined three frequencies of variability in SST and tide-gauge data in the California Current between $45^{\circ} \mathrm{N}$ and $22^{\circ} \mathrm{N}$ (5-7 year period, a 20-30 year period and a very low frequency signal on the order of 60 years) and concluded that all three are related to the variability of the atmospheric Aleutian Low phenomenon. The area of interest, however, was much smaller than what is being discussed in this paper, primarily the area defined in this paper as sub-regions one and four. In one phase, the flow into the California Current from the North Pacific Current is relatively weak and is also associated with an intensification of the Alaska Current. The California Counter Current, with relatively higher sea level temperatures and heights, may also have more frequent mesoscale eddy formation during this phase. In another study, Tanimoto et al. (1993) examined 37 years of sea surface temperature data at three periods: 24 months, $2-5$ years, and greater than 5 years. They found that the SST field at the highest and lowest frequencies had similar spatial patterns of variability, while the 2-5 year band represented El Niño-Southern Oscillation (ENSO) events with a southward shifted spatial pattern. The analysis statistically quantified the data over the North Pacific as a whole, rather than just the Northeast Pacific, the focus of this paper.

Several atmospheric based indices are referenced to in this paper. Two of the indices, the Aleutian Low Pressure Index (ALPI) and the Pacific North-America (PNA) index describe the state of the atmosphere and its low frequency variations. The ALPI (Beamish et al., 1997) is the anomalous (referenced to a long-term average) area average sea-level pressure over the North Pacific. It is a measure of the area extent of low pressure over the basin. For this paper, the average relative intensity between December and February is used. A positive value indicates a strong Aleutian Low. The PNA index (Barnston and Livezey, 1987) is the average over 3 months (January through March) of the amplitude associated with the loading pattern as defined by a rotated empirical orthogonal function analysis of $500 \mathrm{mb}$ heights for the Northern Hemisphere. While the PNA is similar to the ALPI, it describes a pattern of variability that extends further south to the equator and is primarily influenced by the pressures over North America rather than just changes over the North Pacific. The third index, are winter averages (DecemberFebruary) of the Multivariate ENSO Index (MEI) (Wolter and Timlin, 1993). This index is based on the variability of six parameters: sea level pressure, $u$ and $v$ components of the wind, SST, surface air temperatures, and cloudiness. Empirical orthogonal function analysis is used to define the common dominant signal of the set of variables. All these indices can be used to describe some of the variability in the Northeast Pacific but can be enhanced by regional indices based on the ocean's variability. This will be discussed in the following sections.

\section{Data and methods}

\subsection{Data set description}

The data used in the following analysis is the gridded, joint altimeter data set processed by the AVISO group in France (Ducet et al., 2000). The product combines data from several altimeters, TOPEX/Poseidon, Jason-1, ERS-1/2, Envisat, and GFO (Geosat Follow-on) to create an integrated spatial estimate of global SSH anomalies on a weekly basis. The weekly merged gridded SSH anomaly fields (the long-term mean of the 1993-1999 SSH plus geoid has been removed) are then averaged onto a 1-degree uniform grid for easier manipulation. The data covers the period from 1993 through 2007. The paper focuses on three bands of variability: a short period band between 3 and 9 months, a middle band of 2-3 years and a long period band of 4 to 6 years. For the purposes of this study, any long-term trend has been removed as well as the annual cycle prior to further analysis using a band-pass filter. Also, signals with a period of less than three months have been removed.

For this study, the area of interest is between $15^{\circ}$ and $65^{\circ} \mathrm{N}$ and between $200^{\circ}$ and $250^{\circ} \mathrm{E}$ in the Northeast Pacific. Figure 1 shows the study area and its bathymetry. Within this larger region are areas referred to as sub-regions. The subregions include three coastal regions: 1 - south of $42^{\circ} \mathrm{N}$, 2- north of $41^{\circ} \mathrm{N}$ (near Cape Mendocino) and 3- south of Alaska, and three other regions: 4- a region to the west of the coastal California region, 5- a "southern gyre" region west of area 4 and south of about $40^{\circ} \mathrm{N}$, and 6- a subpolar area. The areas are numbered in Fig. 1 and defined based on the similarity and continuity of the energy levels. The areas are not meant to be exact in their size or extent. Rather they are used to help guide the reader through the discussion of the analysis of the signals.

\subsection{Method for analyzing the temporal signal}

The analysis of Tanimoto et al. (1997) used empirical orthogonal functions (EOF) to examine the variability of sea surface temperatures (SST) within three different frequency bands, while the LLuch-Belda et al. (2003) paper examined a portion of our area by filtering the area average of several quantities (SST, tide-gauge SSH). This research examines the variability of a signal within three separate and distinct frequency bands and analyses: a fifteen year altimetric data set of sea surface height (SSH) anomalies, rather than SST field. And rather than using a broad-band filter which tends to smear out the signal, this analysis uses wavelet methodology to isolate the variability within frequency bands. Unlike SST, SSH reflects more than just changes in the surface fields of the ocean. Because the SSH signal represents some measure of an integrated signal of the ocean's circulation field in the top 500-1000 $\mathrm{m}$ of the ocean, it should reflect a more robust measure of circulation changes. 
The wavelet methodology describes the spatial distribution of the SSH variability and its significance in time both within and between frequency bands. Wavelet analysis allows us to look at how the dominant modes vary temporally. An indepth description of wavelet analysis, the application of it, and an extensive discussion of how to determine the significance of the results are given in Torrence and Compo (1998). Users are referred to this paper for detailed questions about the method. The method is becoming widely used to analyze a variety of geophysical signals on a wide range of scales. For example, Gu and Philander (1995) used the method to examine the ENSO signal. Meyers et al. (1993) examined ocean wave dispersion, and others have used the method to analyze wave growth (e.g. Liu, 1994). Tokmakian and McClean (2003) used wavelets to examine the realism of SSH in high resolution ocean models as compared to satellite data.

Similar to windowed Fourier transforms, wavelet analysis allows the localized and dominant frequencies (for which a predetermined scaling can not be defined) to be determined. Given a time series $x_{n}$, where $n=0 \ldots N-1$ and equal temporal spacing, $\delta t$, let $W_{n}(s)$ define the wavelet transform such that

$$
W_{n}(s)=\sum_{n^{\prime}=0}^{N-1} x_{n^{\prime}} \psi^{*}\left[\frac{\left(n^{\prime}-n\right) \delta t}{s}\right],
$$

where $(*)$ indicates the complex conjugate and $\psi$ defines the "wavelet function" which we are using. The wavelet pattern is constructed by varying the wavelet scale, $s$ and translating it along the time index $n$. This pattern shows the amplitude of features versus the scales and how the amplitude changes in time.

$\psi$, the wavelet function, can be defined in an infinite number of ways, but it must have zero mean and be localized in time and space (Farge, 1992). Torrence and Compo (1998) give a detailed discussion on how to choose an appropriate wavelet function. This analysis is done using a Morlet wavelet function, a plane wave modulated by a Gaussian curve where

$\psi(\eta)=\pi^{-1 / 4} e^{i \omega \eta} e^{-\eta^{2} / 2}$,

where $\omega$ is a non-dimensional frequency, defined in this case as equal to 6 .

Because the chosen wavelet function is complex, the transform $W_{n}(s)$ is complex. The transform, thus, can reveal information about both the amplitude $\left(=\left|W_{n}(s)\right|\right)$, and phase $\left(\tan ^{-1}\left[\Im\left\{W_{n}(s)\right\} / \Re\left\{W_{n}(s)\right\}\right]\right)$. The wavelet power spectrum is defined as $\left|W_{n}(s)\right|^{2}$ and for comparisons, different wavelet are normalized by their variance. This gives a sense of the magnitude of the signal relative to white noise.

With the use of wavelets, the filtering function, in this case, a Morlet wavelet (a modified Gaussian), has two degrees of freedom. Because wavelets are local functions, degrees of freedom calculations are very different from the equivalent Fourier methods. The intensity of the signal changes with

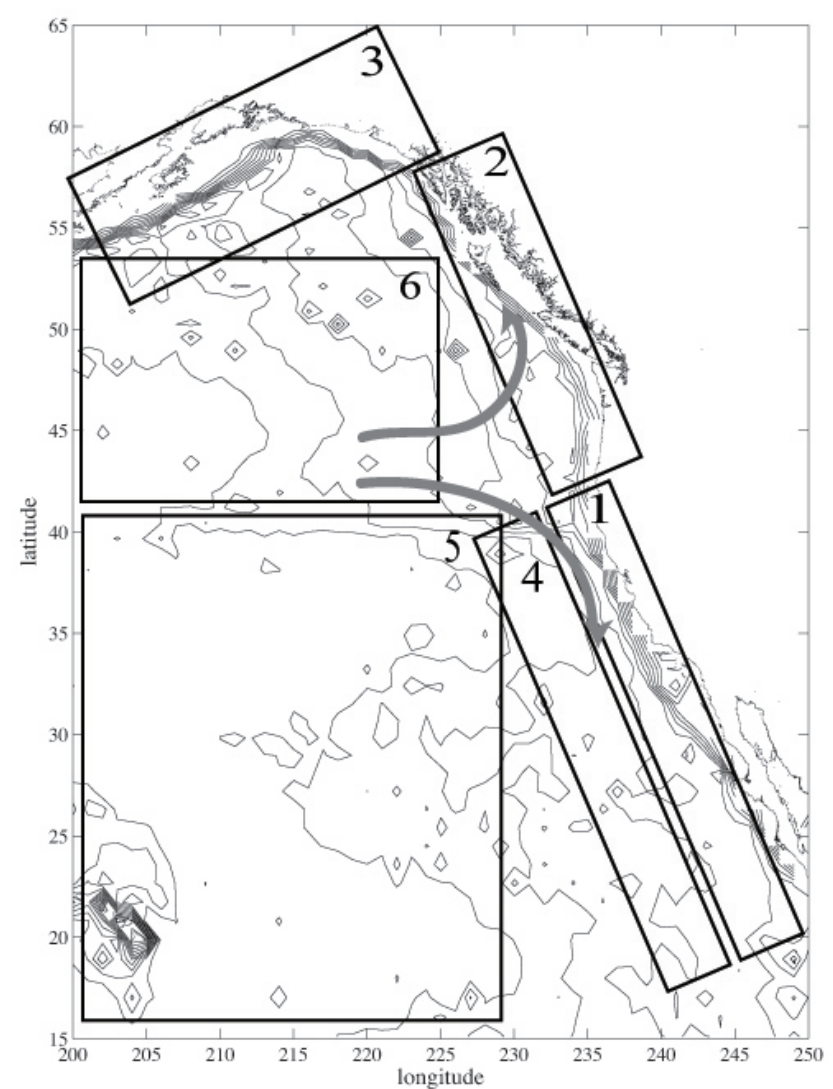

Fig. 1. Area of interest of the Northeast Pacific. Grayscale defines the bathymetric depths as defined in Smith and Sandwell (1996). The contours represent the 0 to $5000 \mathrm{~m}$, increments of 500 . The thick gray lines indicate the general flow of the North Pacific Current (or Drift), splitting into the California Current southwards and the Alaskan Current northwards.

time, and therefore, its local significance. At low frequencies (in this case the 4-5 year band and the use of cyclic boundary extensions) significant peaks in energy can be determined.

When determining which portion of the signal is significant (95\% level), an assumption can be made regarding the redness of the spectrum. Torrence and Compo (1998) estimate the background "redness" coefficient $(\alpha)$ for modelling the NINO-3 spectrum by calculating the lag-1 and lag- 2 autocorrelation coefficients of the data. If

$x_{n}=\alpha x_{n-1}+z_{n}$

describes the time series where $\alpha$ is defined as $(R(1)+\sqrt{(} R(2)) / 2$ and $R(1)$ is the lag-1 autocorrelation of $x, R(2)$ is the lag-2 autocorrelation of $x$ and $z_{n}$ is a Gaussian white noise addition to the signal, then the mean power spectrum can be defined as

$$
P_{k}=\frac{1-\alpha^{2}}{1+\alpha^{2}-2 \alpha \cos (2 \pi k / N)},
$$

where $N$ is the length of the series and $k$ is the spectral point. If a point of the wavelet spectrum is greater than the $95 \%$ chi- 
square distribution curve for this mean spectrum, the signal is significant. A further explanation, with respect to wavelets, is that for a $95 \%$ confidence level in a random time series, $5 \%$ of the values will be above the significance level by chance. Thus, within a band of interest, we want to find signals that are significant as compared to the background signal. In other words, we are trying to identify signals that are not random. The $\alpha$ term can be used to identify those areas within a specific band that are distinct from the background signal of the band. Torrence and Compo (1998) suggest two things to look for in a wavelet spectrum to subjectively determine if the signal is significant: 1) the power concentrated during certain periods of time and 2) the period of concentration changes with time. The influence of the effects of the boundaries of the time series is reduced by extending the original time series in a cyclic manner and, thus, no edge influence is denoted on individual wavelet plots that are shown.

\section{Results}

\subsection{General pattern of the mean variance}

The overall variance of the data is first computed over the spatial domain. This characterizes the general SSH signal before the deconstructed signals are shown in time and space. Because the time period (1993-2007) covered by this study includes a strong El Niño (1997/1998), Fig. 2 shows variance maps of SSH for the data with and without the 1997/1998 period. This has been done to identify the spatial extent of the spectral influence of this event. Figure 2a shows the variance for a thirteen year period: 1993-2007, minus 1997 and 1998, while the figure on the right (Fig. 2b) shows the variance for the full fifteen years 1993-2007.

Generally, both examples of variance show that there are distinct areas where the energy level related to SSH is quite small. These areas are 1) along the coast, in the boundary region and east of the shelf break, 2) in the mid-gyre area of the North Pacific, both north and south of the location of the North Pacific Current, and 3) in an area centred around $240^{\circ} \mathrm{E}$ and $20^{\circ} \mathrm{N}$. The $1997 / 1998 \mathrm{El}$ Niño tends to bias the data in some areas over this relatively short time series. The two averages are similar, but differ in the westward extent of the high variance signal between $30^{\circ}$ and $40^{\circ} \mathrm{N}$ seen in Fig. 2b. In addition, the energy in the SSH signal is greatly enhanced in the southeast corner of the region of interest in Fig. 2b with the 1997/1998 El Niño. This illustrates how the 1997/1998 El Niño contributes to a more westerly extent of enhanced variability. During the fifteen year period, there were several other smaller and but much less significant El Niño events (occurring in 1994/1995, 2002/2003, and 2004/2005) that do not increase the energy levels in a similar manner.
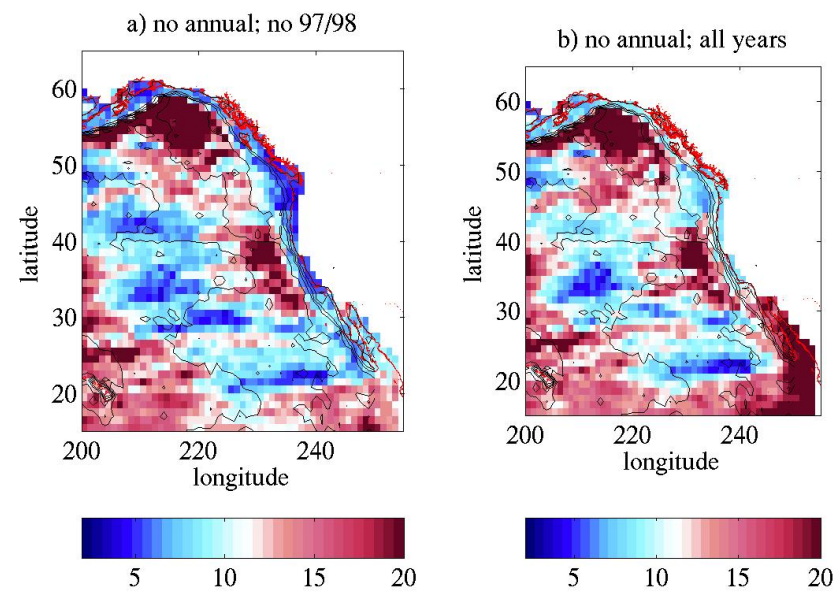

Fig. 2. Variability of (a) 13 years (removal of 1997/98) of SSH altimeter data and (b) +15 years. Units are $\mathrm{cm}^{2}$. Black contour lines denote bathymetric contours in increments of $1000 \mathrm{~m}$.

\subsection{Spatial structure of spectral bands and areal mean temporal evolution}

First, before examining the decomposed SSH signal for a specific location, the patterns of variability in specified frequency bands across the entire region are mapped and examined. The three bands examined are: 3-9 months, 2-3 years and 4-6 years. Maps of the average spectral energy are created by decomposing the SSH anomaly time series at each location into its spectral bands, determining the significance of the signal in the resulting field, and then finding the average over time of the spectral energy at a location. In contrast to other analyses that decompose time series into patterns (e.g. empirical orthogonal functions), this methodology allows for the significance of the signal at a location to be quantified. The significance level was determined as described in Sect. 2.2. For computing the significance of a signal within a band, each band used a different background coefficient $(\alpha$ or redness) for the autocorrelation of that part of the spectrum. At high frequencies, $\alpha$ was set to 0.3 , for the 2-3 year band, a value of $\alpha=0.7$ was used, and for the lowest frequencies, $\alpha$ was set to 0.9 (see previous section for the definition of $\alpha$ ). The values are chosen to identify the peaks in the specific portion of the spectrum. The values do not have to be precise, rather they are chosen as to how "red" the section of the spectrum appears when examining spectral plots of the filtered time series.

Figure 3 shows the maps for each of the three bands: locations with insignificant signal are blank. These maps quantify the importance of a specific temporal scale in a region. Figure 4 shows the associated time series for the maps in Fig. 3. The vertical lines denote the approximate times of an El Niño (1994/95, 1997/98, 2002/03, see http: //www.cdc.noaa.gov, multivariate ENSO index, Wolter and Timlin, 1993). The different lines on each plot represent averages over different areas as specified in the legend. The 
a) $0.3-0.8 y r$ band
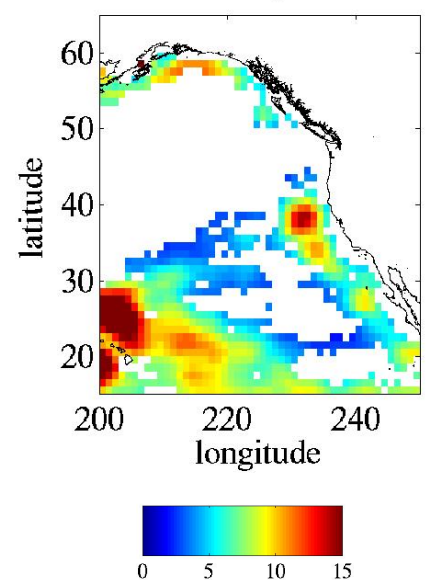

b) 2-3yr band
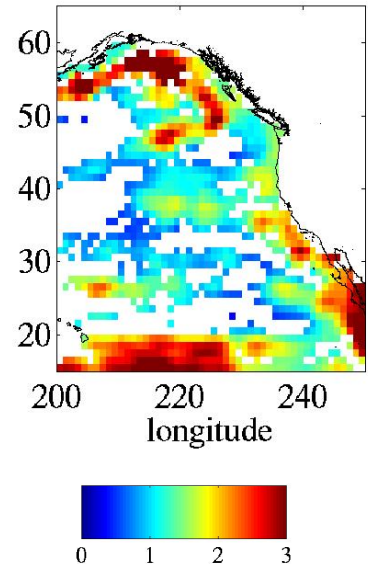

c) 4-5yr band
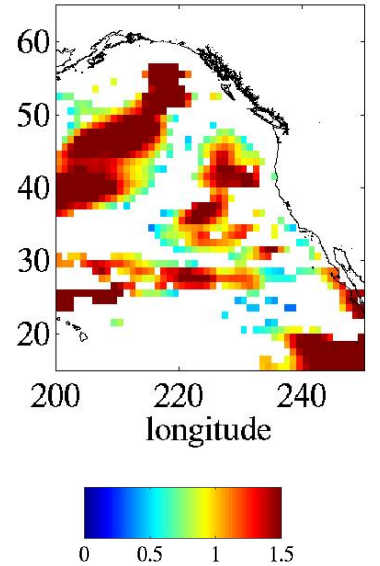

Fig. 3. Spatial maps of significant variance (greater than 0.9) allocated to three bands (a) $0.3-0.8$ years (b) 2-3 years and (c) $4-6$ years. The units of variance are relative and non-dimensional.

time series show the temporal relationships between regions at the three frequencies. The regions are discussed in the following paragraphs.

The SSH variance in the 3-9 month band (Fig. 3a) is high south of $30^{\circ} \mathrm{N}$ in the west and along the eastern boundary south of $40^{\circ} \mathrm{N}$. The eastern boundary area extends westward about $5^{\circ}$ (or $500 \mathrm{~km}$ ). An area of insignificant signal in this band clearly separates these two regions of high variance. In the north, the area of high variability extends southward about $2^{\circ}$ or $200 \mathrm{~km}$ from the coast. The regions closest to the coast have relatively low energy as compared to further offshore. The pattern for the 3-9 month band is reminiscent of the Pacific Decadal Oscillation (PDO, Mantua et al., 1997) and the PNA spatial patterns within the central gyre. However, the temporal variability of this pattern does not reflect the PDO. In this example, the central gyre region has insignificant energy at periods less than a year in contrast to the area along the edges and in the southwestern section of the domain. The corresponding temporal plot of the signal south of $40^{\circ} \mathrm{N}$ (Fig. 4a), compares the temporal pattern for the signal east and west of $230^{\circ} \mathrm{E}$ (comparing region 5 with the area covering the two coastal regions 1 and 4). For each, there are several periods in time that have relatively high signal levels (greater than 1) in the 3-9 month band (1993, 1997-1998, 2000, 2004, and 2006). There are also periods of significantly lower variance, primarily around 1996, 1999 and 2005. The largest differences in the amplitudes of the two time series are during the periods of relatively low overall signal strength (e.g. 1995/1996, 1999). The two time series are correlated such that $29 \%$ (the square of the correlation value) of the variance signal is similar between the two areas at a 7 day lag or 1 point in the time-series, suggesting the overall large scale atmospheric pattern is influencing both the western and eastern areas in a similar way (because of the correlation of around 0.54 ) to some degree. a) temporal evolution $0.3-0.8 \mathrm{yr}$ band

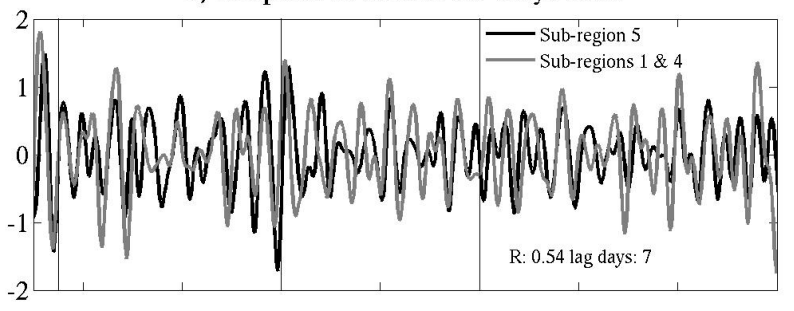

b) temporal evolution 2-3yr band

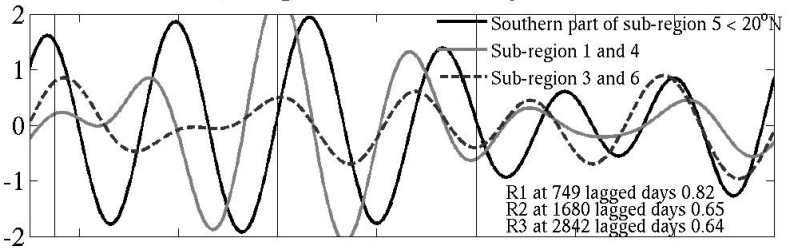

c) temporal evolution $4-5 \mathrm{yr}$ band

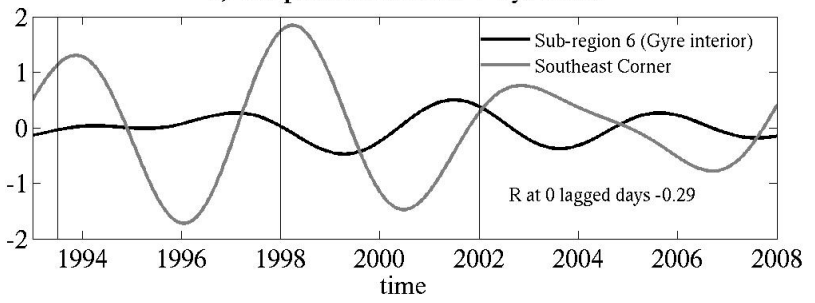

Fig. 4. Average temporal change in variance for three bands (a) 0.3-0.8 years, (b) 2-3 years, and (c) $4-5$ years. Each plot shows estimates of the amplitude time series for two distinct areas of the spatial map for a frequency. The vertical lines denote the approximate dates of relatively strong El Niños. The " $R$ " values for (a) denotes the maximum correlation value between the two lines of each plot. For (b), R1 is the maximum correlation between the southern portion of sub-region 5 and the coastal sub-regions 1 and 4, R2 is between the southern portion of sub-region 5 and the northern sub-regions 3 and 6 and R3 is between the southern coastal subregions 1 and 4 and the northern sub-regions 3 and 6 . For (c) the $\mathrm{R}$ value is the zero-lag correlation value. The amplitudes have no units. 
The 2-3 year band map of SSH variance (Fig. $3 b$ ) reflects the strong El Niño events in the tropical region and along the California Coast up to a latitude of approximately $35^{\circ} \mathrm{N}$. The temporal evolution of the 2-3 year signal for the eastern, more coastal area (Fig. 4b, gray line, average over subregions 1 and 4), identifies the strong 1997/98 El Niño, but it also indicates significant energy levels in 1995 and 2001 that are related to some other events within the band other than an El Niño. (Note that 1995 is a weak El Niño year and 2001 is a weak La Niña year.) The southern area of high variance (west of $230^{\circ} \mathrm{E}$ and south of about $20^{\circ} \mathrm{N}$, the black line in Fig. 4b, the southern portion of sub-region 5) leads the coastal signal by about 2 years over the full time series, determined by the maximum correlation value of 0.82 (R1) at 749 days; (correlation between black and gray lines). However, for the period of time between 1995 and 2002, the two series have a maximum correlation of about 7 months, a period of time that contained two positive ENSO events, one of which was the dominant signal over the complete time series.

The dashed line in Fig. $4 \mathrm{~b}$ (representing sub-regions 3 and 6), clearly illustrates how the northern area, north of $45^{\circ} \mathrm{N}$ is not similar to either the more southern coastal subregions offshore and south of $45^{\circ} \mathrm{N}$, nor the temporal evolution of the tropical El Niño events. The correlation of this northern area with that of the area south of $20^{\circ} \mathrm{N}(\mathrm{R} 2)$ and the correlation between the northern regions (sub-regions 3 and $6)$ and the coastal sub-regions (R3) give values that are not significant $(0.65$ and 0.64 for $95 \%$ probability with 6 degrees of freedom due to the filtering and sampling). Therefore, over the whole of the region of the Northeast Pacific, the signal in the two to three year period is partly a manifestation of ENSO and partly of events unrelated to ENSO. These events may be related to large scale spatial forcing that occur over the whole of the northeast Pacific as indicated by the coincident signal in all three (grey, black, and dashed lines) after 2005. Thus, only under some conditions when the signal is large can one region be used to "predict" changes in another area.

The third frequency band examined, the 4-6 year band (Fig. 3c) and its associated temporal evolution (Fig. 4c), shows a structure unlike the other two bands. The spatial pattern gives an indication of locations where low frequency changes in the ocean's circulation might be detectable, for example, around $47^{\circ} \mathrm{N}$ and $210^{\circ} \mathrm{E}$. It is important to note that the central area $\left(200-210^{\circ} \mathrm{E}\right.$ and $\left.35-50^{\circ} \mathrm{N}\right)$ shows significant energy in this band with little or no significant energy for the other bands. The high values in the lower right of the spatial domain reflect the dominant 1998 El Niño. The area is unrelated to the coastal areas as illustrated by the time series for the two (Fig. 4c) which are not correlated. a) Wavelet Power Spectrum 238E 37N

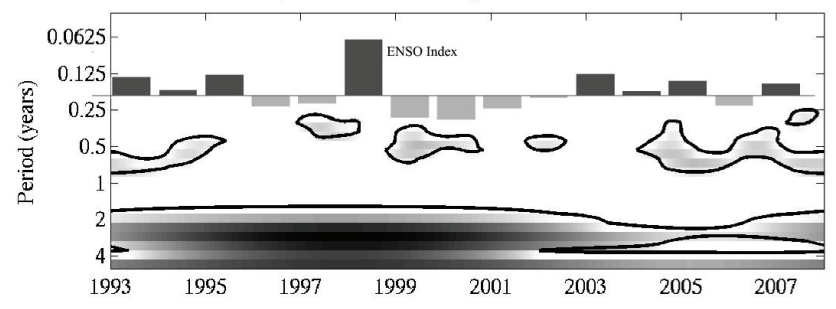

b) Wavelet Power Spectrum 231E 51N

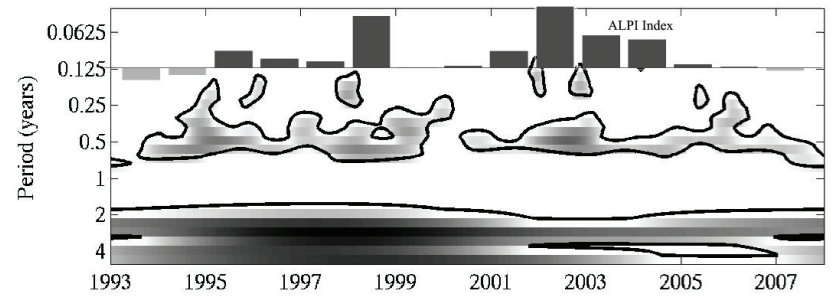

c) Wavelet Power Spectrum 215E 56N

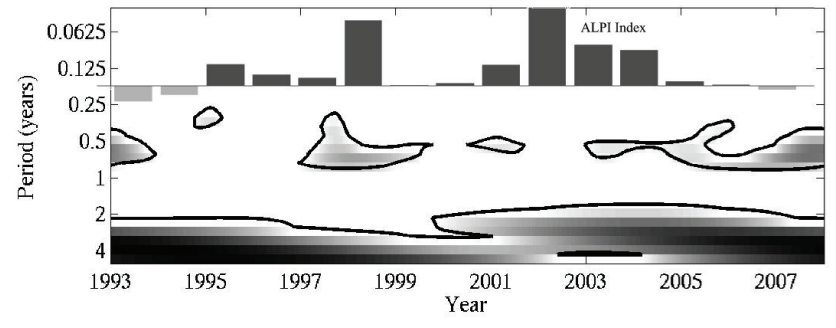

Fig. 5. Wavelet spectral variance of three coastal locations: (a) at $238^{\circ} \mathrm{E}, 37^{\circ} \mathrm{N}$ (seasonal signal removed and detrended) wavelet distribution, (b) at $231^{\circ} \mathrm{E}, 51^{\circ} \mathrm{N}$, (c) at $215^{\circ} \mathrm{E}, 56^{\circ} \mathrm{N}$. The areas of white are insignificant. The significant signals are shown with the gray shading indicating relative strength - darkest being the strongest. The bars on (a) represent the relative strength of the ENSO index. On (b) and (c), the bars indicate the relative strength of the ALPI index.

\subsection{Examples of individual area spectra}

\subsubsection{In coastal regions 1,2 , and 3}

To better understand the SSH energy distribution in time, examples of the decomposed signals are shown for a set of locations in the coastal regions (Fig. 1). In these areas, the energy close to land is relatively low as compared to further offshore, especially when the 1997/98 period, the extreme El Niño years, is excluded (see Fig. 2). Most of the energy for the coastal area is within either the first band (3-9 months) or the 2-3 year band (Fig. 3).

A typical wavelet decomposition of the time series for the SSH anomaly at a point in region $1\left(238^{\circ} \mathrm{E}, 37^{\circ} \mathrm{N}\right)$, Fig. 5a shows a distinct and strong response to the 1997/1998 El Niño in the longer period signals of the spectrum (2 years and greater). There is a noticeable lack of energy towards the end of the time series in these longer period bands. Within the shorter period band of 3-9 months, the significant energy 
peaks are in the years 1995, 1998, 1999, and late 2004-2007. The energy is unrelated to the ENSO index as denoted by the bars above the spectrum.

The second time series decomposition, at a location further north at $231^{\circ} \mathrm{E}, 51^{\circ} \mathrm{N}$ in region 2 (Fig. 5b), shows the El Niño signal, again, dominating the energy decomposition wavelet plot (darkest gray area). There is less energy in this band in the latter half of the record (years 2000-2005) than in the early period (1993-1999) for the 2-3 year period, similar to the signal at $37^{\circ} \mathrm{N}$. The secondary signal is for the 3 to 9 month band that has significant energy across most of the years. When the ALPI index (shown by the bars on the figure) is highest in the second half of the record, the longer periods have less energy. The enhanced energy in 1998 is due to the unusually strong 1997/1998 El Niño. A positive ALPI value indicates a strong low pressure pattern and is coincident with the period of time that has increases in energy at the shortest periods ( 0.125 years) in 1998, 2002 and 2003.

At a third location, along the Alaskan coast and within region $3\left(215^{\circ} \mathrm{E}, 56^{\circ} \mathrm{N}\right)$, there is no indication of the strong El Niño in the 2-3 year band (Fig. 5c). The time evolution is dissimilar to the other two coastal regions at the longer periods. In the 2 to 3 year period band, there is a significant energy in the latter half of the record, centered in 2006, coincident with the lower values of the ALPI (shown by the bars on the graph). However, the energy distribution centered at the semi-annual period (3-9 months) is significant in the years that are consistent with the strong 1997/1998 El Niño, but not confined to that period. The intense 1997/1998 El Niño contributes to the variability at this northerly latitude, but, in general, the ENSO influence is not evident at this northerly location for other years.

\subsubsection{In the California Current: region 4}

Figure 6 gives an example of a wavelet spectrum for SSH further offshore and within the California Current, west of Fig. $5 \mathrm{a}$ at $232^{\circ} \mathrm{E}, 37^{\circ} \mathrm{N}$. Most of the energy at this location is found at short periods (3-9 months), with much less energy (a much narrower spread across the band) in the 2-3 year band than found in the coastal area. In the shortest period band (3-9 months), there are two distinct periods of significant energy, one between 1993 and 1996 and the second from 2000 through 2006. In the years in between, 1997 through 1999 , the energy is much lower or insignificant and similarly insignificant for the same years for the 2-3 year band. Thus, the variance of SSH in this off shore area does not include an enhancement related to any strong ENSO signal (bars on figure) such as seen in the coastal region. Where there is significant energy, the spread of the energy is broad and across the 3-9 month band. In general, for the years with a positive ENSO index, there is relatively low significant energy across the bands, while in years with a negative index, the tendency is for the signal energy to be higher (e.g. 1996, 1999-2002).

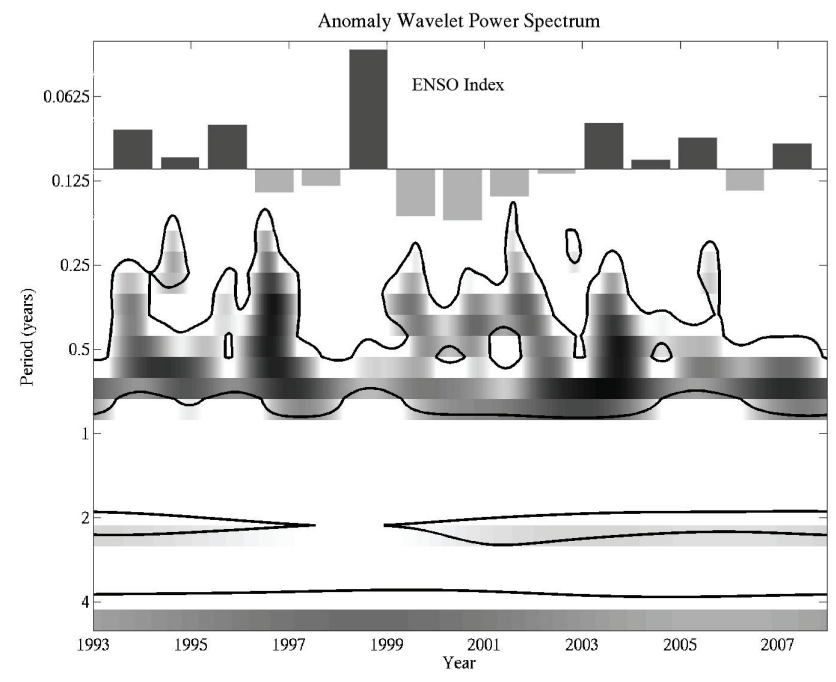

Fig. 6. Wavelet spectral variance at $232^{\circ} \mathrm{E}, 37^{\circ} \mathrm{N}$ (seasonal signal removed and detrended). The areas of insignificant signal are white. The significant signals are shown with the gray shading indicating relative strength - darkest the strongest. The bars represent the relative strength of the ENSO index.

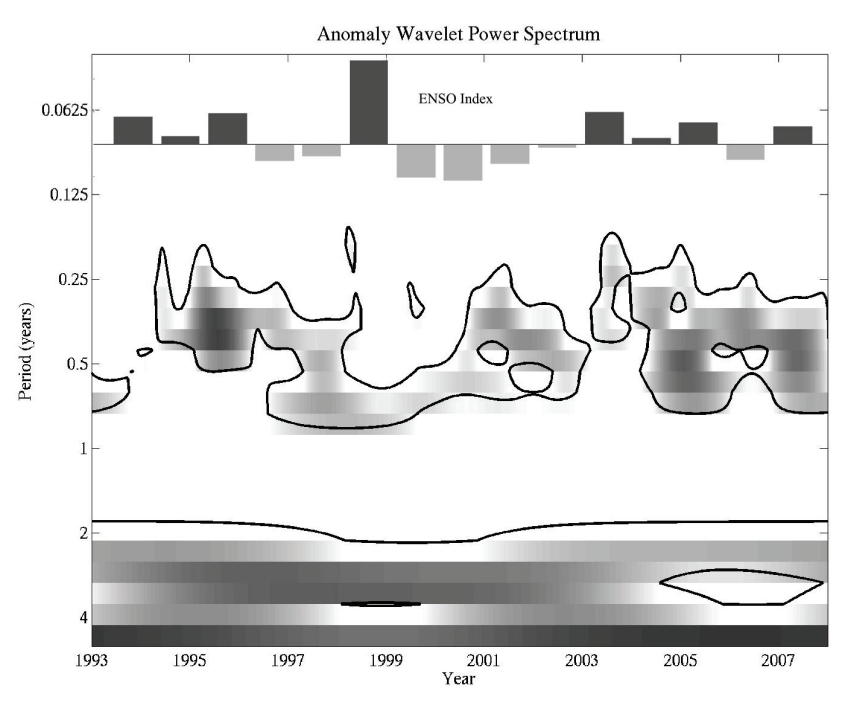

Fig. 7. Wavelet spectral variance at $205^{\circ} \mathrm{E}, 25^{\circ} \mathrm{N}$ (seasonal signal removed and detrended). The areas of insignificant signal are white. The significant signals are shown with the gray shading indicating relative strength - darkest the strongest. The bars represent the relative strength of the ENSO index.

\subsubsection{Region 5}

The wavelet spectrum for a location within region $5\left(205^{\circ} \mathrm{E}\right.$, $25^{\circ} \mathrm{N}$ ) is shown in Fig. 7. At this location there is, again, little indication of an increase in energy that can be clearly related to the 1997/1998 El Niño in the 2-3 year band as indicated by the ENSO index (bars on the figure). The 2-3 year band has a strong signal, but it is unrelated or, perhaps 


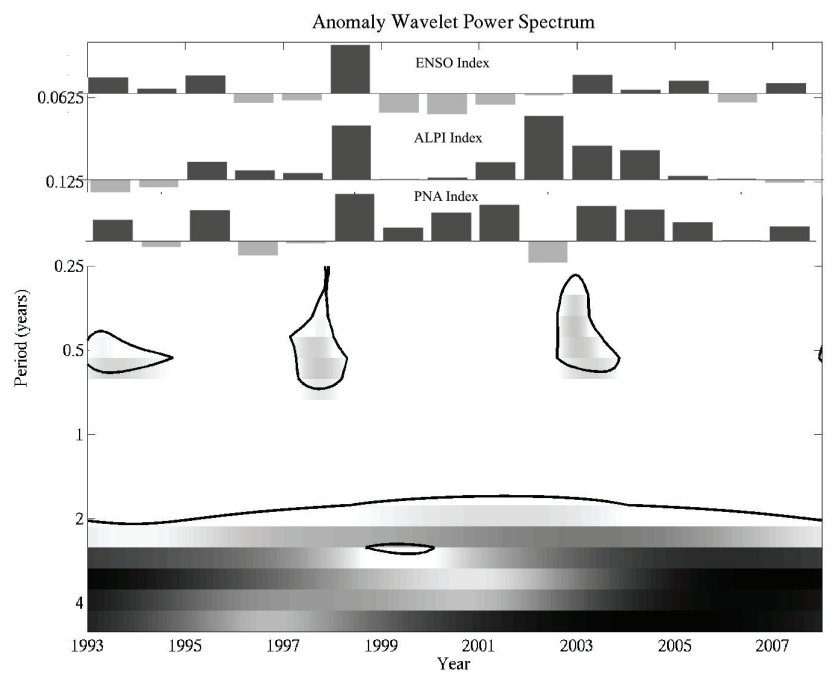

Fig. 8. Wavelet spectral variance at $215^{\circ} \mathrm{E}, 47^{\circ} \mathrm{N}$ (seasonal signal removed and detrended). The areas of insignificant signal are white. The significant signals are shown with the gray shading indicating relative strength - darkest the strongest. The bars represent the relative strength of the ENSO, ALPI, and PNA indices, top to bottom.

anti-correlated with the El Niño event of 1997/1998 as suggested by the reduction in the energy in 1997/1998 compared to the rest of the time series. The 2-3 year band also has a drop in significant energy in the period 2005-2007. The 3-9 month band indicates relatively high energy in 1995, 2001, and 2004-2005 and a reduction in energy across the band for the period spanning 1998 through 2000. There is also a shift of the higher frequency energy towards lower frequencies during the 1998-2000 period (i.e. a shift in the energy centered at 4 months to a signal centered around 7 months). This is a much different pattern of variability than seen at the more coastal locations, but similar to the signal in region 4 .

\subsubsection{In the subpolar gyre: region 6}

In the subpolar gyre, the dominant frequency is the lowest band, periods greater than 3 years, as shown in Fig. 8. At the location, $215^{\circ} \mathrm{E}, 47^{\circ} \mathrm{N}$, there is also significant energy, over relatively short periods of approximately a season, found in the 3-9 month band. These energetic signals appear related to a positive ENSO index but not all positive ENSO years show a significant energy increase in this band. The energy in this short period band is somewhat cyclic, with peaks every 3 to 4 years or so. This pattern is consistent with high values of the ALPI index in years 1998 and 2003, but not in 2002, which also has a relatively high index value. The low PNA index for 2002 indicates a relatively high surface pressure over the larger area defined by the index. These two indices suggest that while the variability of the whole of the North Pacific is associated strongly with a weak PNA pattern, the ALPI value reflects another extreme making it difficult to understand the importance of these two indices on the ocean signal. The wavelet decomposition also indicates that there is no significant signal related to the strong 1997/1998 El Niño in the 2-3 year band. Rather than showing intensified energy in 1998 and then relaxing after 1998, the energy in the 2-3 year band is high through the end of the time series. In addition, in the shorter period 3-9 month band, there is little energy in the period between 1999 and 2001, but a significant signal in the year 1998 and also in 2003.

\subsection{Inter-regional connections}

To understand how regions within the ocean may be related and to further understand how changes within the ocean might be predicted, maps of spectral energy within the bands are plotted in time across a band of latitudes or longitudes.

\subsubsection{South to north connections: relating region 1 to regions 2 and 3}

As shown in the previous figures, within the 2-3 year band, there is significant indication that the energy is mostly associated with the strong El Niño of 1997/1998. To more fully examine the south to north connections, a latitude/time plot is created from individual spectral decompositions along the coast. Plotting the significant energy, starting from the southern boundary, within the 2-3 year band that occurs within $1^{\circ}$ of the coast, the ENSO influence on the signal is observed to move up the coast (Fig. 9a). The energy signal associated with the 1997/1998 El Niño is illustrated by highlighting the points of maximum energy during the winter of 1998 with the gray line on the figure. This distinct signal extends northward to about $40^{\circ} \mathrm{N}$, but beyond this point, the significant energy pattern in this band is weaker and appears to be unrelated to the propagating signal south of $40^{\circ} \mathrm{N}$. The signal found north of $45^{\circ} \mathrm{N}$ does not reflect a propagating signal. This portion of the energy signal represents the ocean's local response to a large scale, sustained atmospheric event associated with the large 1997/1998 El Niño, rather than any internal ocean process such as Kelvin wave contributions to the variance of SSH.

The figure also illustrates areas where the signal is modified by smaller areal changes, such as from very local wind stress, as indicated by the increase in the energy levels, for example, around $32^{\circ} \mathrm{N}$ and $37^{\circ} \mathrm{N} .32^{\circ} \mathrm{N}$ is in the area complicated by the islands within the Southern California Bight and $37^{\circ} \mathrm{N}$ is about the location of San Francisco, with its complicated topography. $40^{\circ} \mathrm{N}$ is the area of Cape Mendocino. There is also an increase in energy at the latitude of Cape Blanco (approximately $43^{\circ} \mathrm{N}$ ).

In contrast to the longer period band, the shorter 3-9 month time/latitude map (Fig. 9b) shows how the energy signal is reflecting locally forced events (e.g. between $35^{\circ} \mathrm{N}$ and $\left.41^{\circ} \mathrm{N}\right)$. Only at the southern boundary does the energy within 

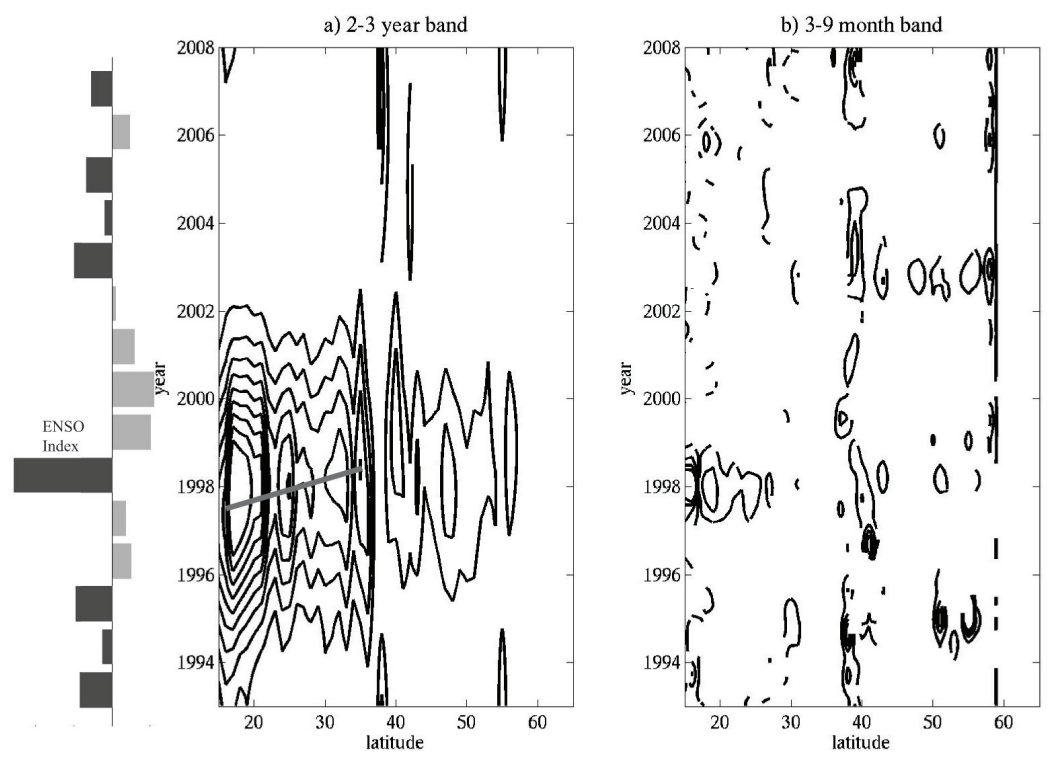

Fig. 9. Contours of significant SSH variance within (a) the 2-3 year band and (b) the 3-9 month band. Each is for points within 1 degree of the coastline; each contour line is 2 units starting at 3 . The straight gray line in (a) indicates the temporal evolution of the maximal energy in this band and its northward propagation with time. The bars on the left represent the relative value of the ENSO index, positive to the left.

this band represent any direct relation to the strong El Niño of 1997/1998. There is little, if any, propagating energy in the signal in this portion of the spectra. It clearly shows the contrast to the 2-3 year band in energy showing how the 3-9 month band dominates the signal at $40^{\circ} \mathrm{N}$.

\subsubsection{East to West connections: relating regions 1 and 2 to regions 4,5 and 6}

To understand the relationships in the energy signals in the coastal band and further offshore, time/longitude plots are shown for the signals in the 3-9 month band at two latitudes, $37^{\circ} \mathrm{N}$ and $51^{\circ} \mathrm{N}$. Figure 10a indicates that the energy is primarily localized in space with a few periods in time that show limited and narrow offshore propagation. This is consistent with Kelly et al. (1998) and Haney et al. (2001). They suggest the coastal energy signal does not extend offshore in the surface layers, but rather subsurface. For example, at $37^{\circ} \mathrm{N}$, in 1995, the energy is more inshore, while in 1997, in which ENSO dynamics are more energetic, the significant signal extends further offshore. The energy within the coastal and California Current regimes is also distinct from any short period signal generated in the middle of the basin. At $51^{\circ} \mathrm{N}$, the energy in this band is local and significant in the years 1995, 1998, and 2002-2006, both inshore and slightly further offshore and is somewhat coincident with the periods of time with a positive ALPI.

At the southern boundary of the domain $\left(15^{\circ} \mathrm{N}\right.$; Fig. 11a), the time evolution of the SSH spectral signal within the 23 year band shows the energy moving from the west in 1993 and moving somewhat eastward to about $215^{\circ} \mathrm{E}$ (as indicated by the slope of the contour lines at the bottom of the plot) towards 1998, with a strong and stationary signal between $215^{\circ}$ and $230^{\circ} \mathrm{E}$. The eastern most portion of the plot shows another signal that moves from the coast westward, east of $230^{\circ} \mathrm{E}$ and centered about late 1996.

At $37^{\circ} \mathrm{N}$, the evolution of the variance in the 2-3 year band (Fig. 11b) shows an area of high variance near the coast that is related to the 1997/98 El Niño. At this latitude, the figure also shows enhancement of the variance centered around $1997 / 1998$ to the west of $225^{\circ} \mathrm{E}$, indicative of a broad area of similar forcing. The $2-3$ year band at $37^{\circ} \mathrm{N}$ (Fig. 11b) does not show any indication of offshore energy propagation, rather the 2-3 year band indicates a temporally consistent pattern of energy along the latitude band that can be identified with the strong 1997/1998 ENSO event. This pattern is consistent with the findings of Strub and James (2002a-c). They conclude that most of the seasonal change in the upper waters of the California Current is primarily due to advection in the boundary current rather than from the interior of the Pacific.

Further north at $47^{\circ} \mathrm{N}$, the east to west connections are quite evident within the 2-3 year band as shown by Fig. 11c. The most eastern section (greater than $225^{\circ} \mathrm{E}$ ) shows the influence of local forcing conditions on the SSH anomaly exhibited by the extended temporally consistent pattern of energy in the band. West of approximately $225^{\circ} \mathrm{E}$, a local enhancement of the forcing centered in 1998 further shows how the energy appears to propagate westward. The reason for the enhancement at this location may be related to the large change in the topography at about $226^{\circ} \mathrm{E}, 47^{\circ} \mathrm{N}$, the Cobb Seamount (see Fig. 1, Codiga and Eriksen, 1997). There is no such distinct pattern at $51^{\circ} \mathrm{N}$ (no figure shown). 

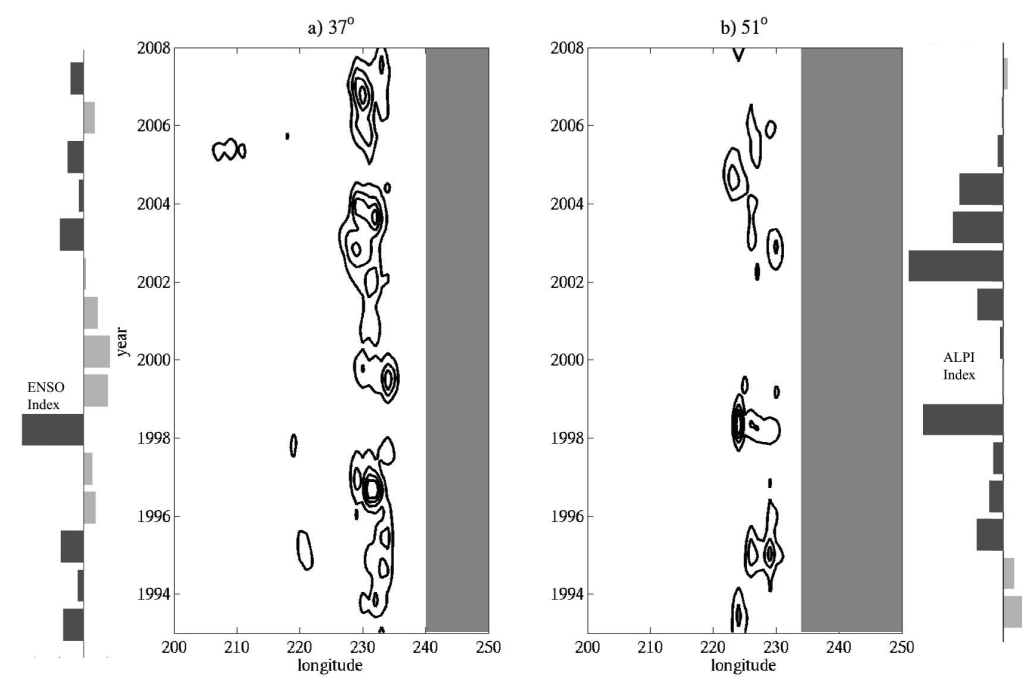

Fig. 10. Contour of significant SSH variance for the 3 to 9 band for zonal points along a given latitude: (a) $37^{\circ} \mathrm{N}$ (region 1 ) and (b) $51^{\circ} \mathrm{N}$ (region 2). The bar graph on the left is the ENSO index and the one on the right is the ALPI index, positive values in black and to the left.

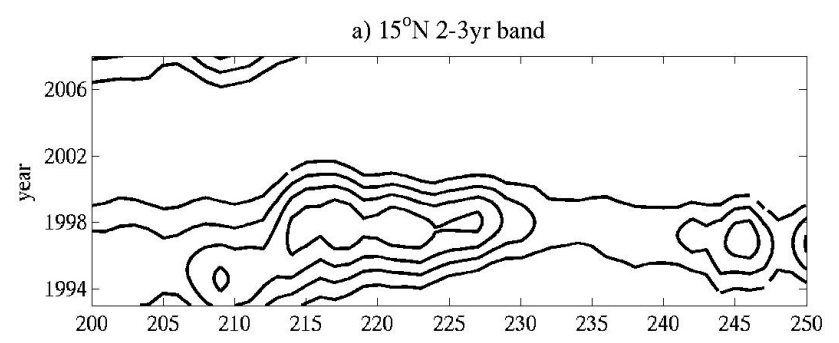

b) $37^{\circ} \mathrm{N} 2-3 y r$ band

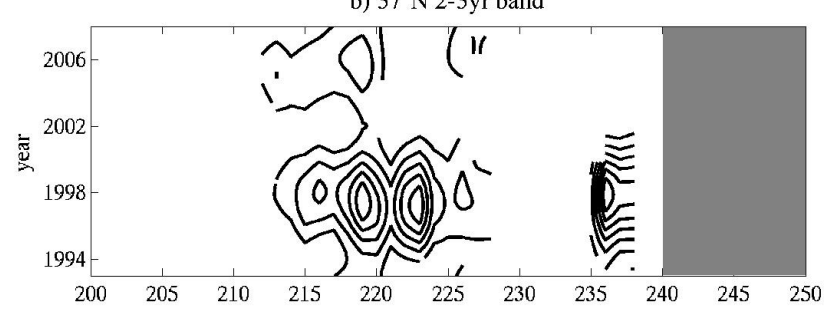

c) $47^{\circ} \mathrm{N} 2-3 \mathrm{yr}$ band

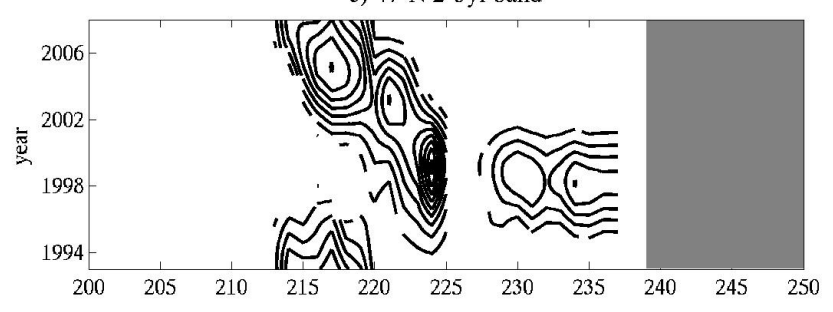

Fig. 11. (a) Contour of significant SSH variance within 2-3 year band at $15^{\circ} \mathrm{N}$; contour lines every 2 units starting at 2. (b) Same as (a), but for $37^{\circ} \mathrm{N}$; contour lines every 1 units starting at 1 . (c) Same as (a) but for $47^{\circ} \mathrm{N}$; contours area every 5 units starting at 5 . The gray shading represents land.
The 4-6 year band, at $15^{\circ} \mathrm{N}$ (Fig. 12a), shows the enhanced signal of the $1997 / 98 \mathrm{El} \mathrm{Niño} \mathrm{at} 230^{\circ} \mathrm{E}$ and clearly propagating eastward to the coast. This large scale, low frequency signal dominates the SSH variability showing the $1997 / 8$ signal extending all the way to the coast. This denotes how the strongest ENSO signal dominates the spectrum over the period of the data in this area.

Quite different spectral signals are present for the band at $37^{\circ} \mathrm{N}$ and $47^{\circ} \mathrm{N}$ (Fig. $12 \mathrm{~b}, \mathrm{c}$ ). At $37^{\circ} \mathrm{N}$, the signal is chaotic with no clear patterns of variance represented in the band as compared to the 2-3 year band discussed in the previous paragraph. However, further north, at $47^{\circ} \mathrm{N}$, there are two areas that show patterns of related significant energy, one east of $220^{\circ} \mathrm{E}$ and the other west of this meridian. Between $230^{\circ} \mathrm{E}$ and $220^{\circ} \mathrm{E}$, the energy pattern indicates a westward propagation of coherent SSH change. The signal extends over a broad area for a long period of time, initially driven by a strong shift in forcing related to the ENSO event of $1997 / 1998$. In the western half (west of $220^{\circ} \mathrm{E}$ ), the plot also shows an extended period of significant variance of the energy in the 4-6 year band (Fig. 12c). The signal is strongest in the west around 2001 and shows the pattern of variance moving eastward.

An examination of the wind stress spectral decomposition for this frequency band, (Fig. 12d), shows a more zonal pattern of energy distribution indicating that the forcing contribution has a zonal structure in time which is consistent across a band of $20^{\circ}$ of longitude. This is in contrast to the pattern of the SSH energy spectrum which shows the maximum location of variance moving eastward in time. Thus, the differences in the patterns of the energy spectrum in this band between the forcing field of the wind stress and that of the SSH field suggest that the ocean signal represents both a local response to atmospheric forcing and a propagating or advective contribution to the variance. 


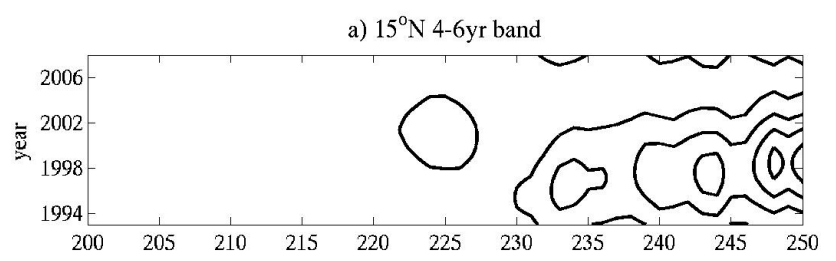

b) $37^{\circ} \mathrm{N} 4-6 \mathrm{yr}$ band

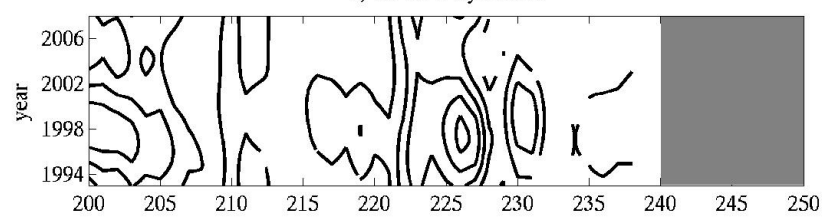

c) $47^{\circ} \mathrm{N} 4-6 \mathrm{yr}$ band

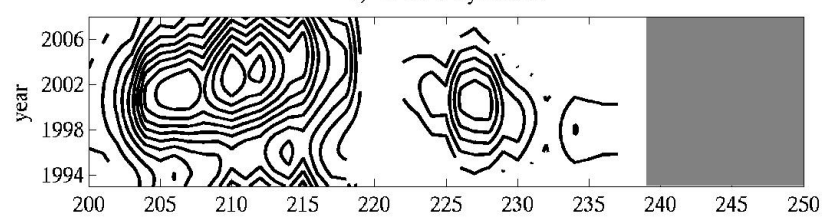

d) Wind stress curl 4-6yr band $47^{\circ} \mathrm{N}$

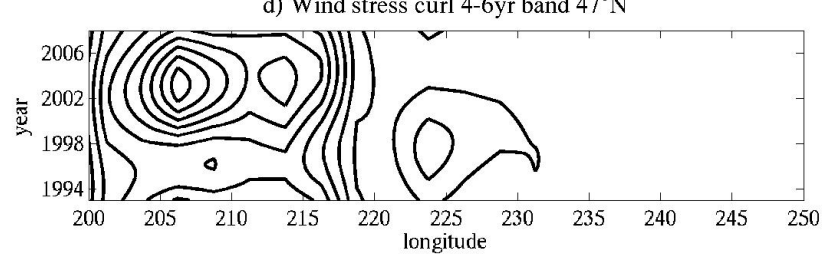

Fig. 12. (a) Contour of significant SSH variance for $4-6$ year band at $15^{\circ} \mathrm{N}$; contour lines every 2 units starting at 2. (b) same as (a) but for $37^{\circ} \mathrm{N}$; contour lines every 1 units starting at 1 . (c) Same as (a), but at $47^{\circ} \mathrm{N}$; each contour line is 1 unit starting at 1 . (d) Contours of significant wind stress curl variance within the 4-6 year band between $45^{\circ} \mathrm{N}$ and $47^{\circ} \mathrm{N}$. The values are computed from ECMWF fields at a resolution of 2.5. Contour lines every 0.005 units starting at 0.01 . Contours are relative. The gray shading represents land.

\section{Discussion}

\subsection{Quantifying upstream and downstream relationships}

It is noted in the first paragraph that the motivation for this work is to explore if there is useful information in the spectral signal relating to the predictability of the ocean's circulation. Capotondi et al. (2005) and Cummins and Lagerloef (2002) explored the influence of Ekman pumping in the Northeast Pacific low frequency changes in circulation, which explains much of the directly forced changes seen in the upper ocean. Both papers, using EOFs to decompose the large scale signal, conclude that at periods longer than 2 years and over large areas, the changes are due to Ekman pumping rather than from changes due to the influence of Rossby waves. This paper examines a similar signal through the decomposition of the
SSH energy spectrum. The decomposition shows, rather than one dominant large area signal, there are distinct characteristics in different regions and in some of the regions, processes other than the low frequency, local wind forced processes are playing a significant role in the ocean's variability. Examining the SSH anomaly signal in this manner allows spatial as well as temporal similarities within one frequency band to be delineated. Further, by using prior knowledge of a change in the upstream SSH field that this decomposition allows for, a downstream future circulation state may be predictable.

The following is suggested of how this spectral information can be used. In the interior of the region of interest (between $20^{\circ} \mathrm{N}$ and $55^{\circ} \mathrm{N}$ ), the most significant energy is in the 2-3 year band and the 4-5 year band. Using Fig. $12 \mathrm{c}$ as an example, the maximum of the significant SSH energy west of $220^{\circ} \mathrm{E}$ appears to propagate eastward in the latter half of the time series with a less energetic signal in the early part of the record. A similar time/longitude plot of the wind stress curl in the 4-6 year band shows a pattern of energy as observed in the SSH anomaly field for this band west of $220^{\circ} \mathrm{N}$ (Fig. 12d) that is stationary across longitudinal space. A covariance analysis shows the highest area of covariance between the wind stress curl and the SSH anomaly 4-6 year spectral energy band is in the area of $210-220^{\circ} \mathrm{E}$ and $45-$ $50^{\circ} \mathrm{N}$ (not shown), consistent with the previous mentioned papers of direct Ekman pumping, but with a much more limited extent. The difference in the two spectral patterns from SSH and wind, suggests that advective properties within the ocean are also an important contribution to the changes in the spectral characteristics of the SSH signal and thus in circulation patterns.

To examine how advection might be contributing to changes seen in the spectral decomposition, geostrophic velocity anomalies were calculated from the SSH fields. For completeness, the anomalous mean velocity field over the 15 years was also computed and is shown in Fig. 13c. The plot shows the general tendency of the anomalous flow over the 15 years. Using the same latitudes as above, $47^{\circ} \mathrm{N}$ and $37^{\circ} \mathrm{N}$, several time series were extracted from the fields. The annual cycle and higher frequencies were removed from the fields before calculating the velocities. Figure 13a) shows the zonal velocity anomalies at $47^{\circ} \mathrm{N} 215^{\circ} \mathrm{E}$ and also the meridional velocities at $47^{\circ} \mathrm{N}, 235^{\circ} \mathrm{E}$, offset 2 months. The plot shows the dominant characteristic of the time series as the "event" centered at 2002. The early part of the record, between 1993 and about 2001, shows low variance in the velocities at the two locations. There is a strong relationship in the signals from 2001 to 2003 and the "trend" is similar in all the series from 2004 until 2008. Figure 13a) cannot be compared directly to Fig. 11c, as the former contains multiple frequencies over a very broad range of frequencies and the latter only shows the very low frequency band. These broadband changes are the result of advection within the ocean and changes also in the large scale atmospheric conditions. 


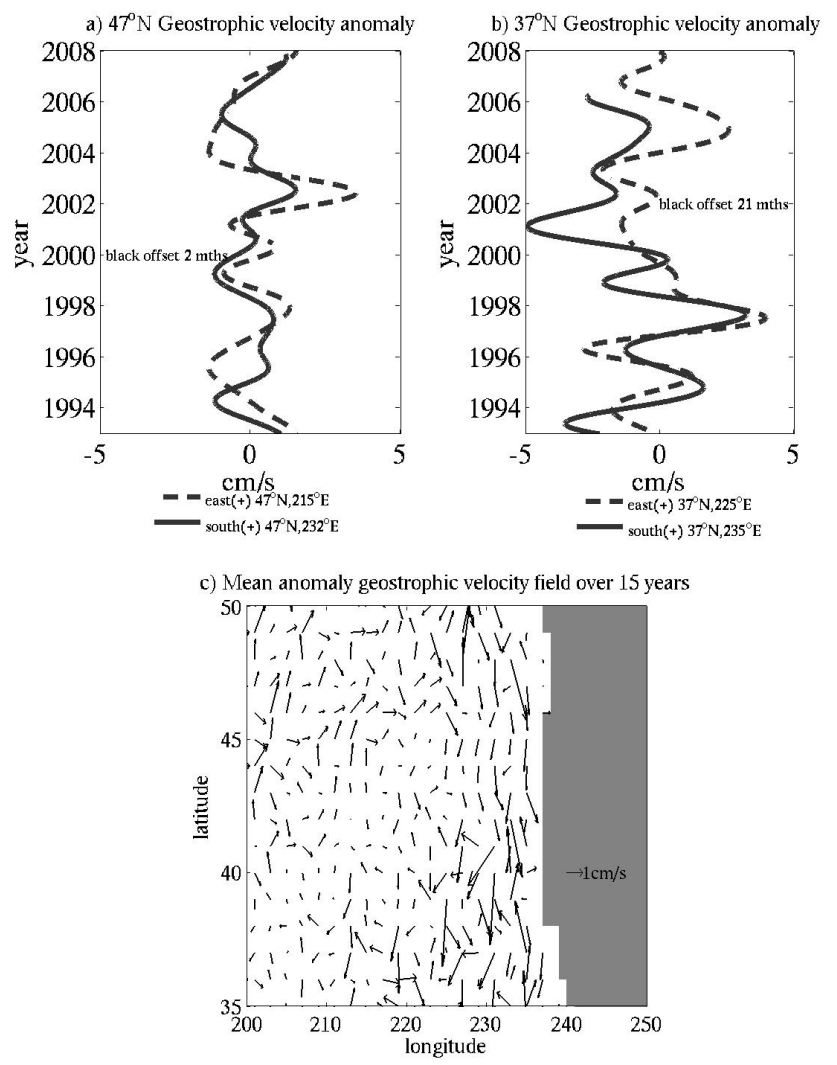

Fig. 13. Geostrophic velocity anomalies at 2 latitudes: (a) zonal velocity at $47^{\circ} \mathrm{N}, 215^{\circ} \mathrm{E}$ (dashed line) and meridional velocity at $47^{\circ} \mathrm{N}, 232^{\circ} \mathrm{E}$, offset by 2 months (black line); (b) zonal velocity at $37^{\circ} \mathrm{N}, 225^{\circ} \mathrm{E}$ (black dashed line) and meridional velocity at $37^{\circ} \mathrm{N}$, $235^{\circ} \mathrm{E}$, offset by 21 months. Annual and higher frequencies have been removed. Offsets determined by lag of maximum correlation in time series between the time series. For completeness, (c) shows the mean anomaly geostrophic velocity field over the full 15 years. Every other grid location is plotted.

This relational information can be used to inform future changes downstream that may not be obvious. For example: at $37^{\circ} \mathrm{N}$ in Fig. 13b, the two curves are lagged by about 21 months, with the western series located at $225^{\circ} \mathrm{E}$ and the eastern, shifted by plus 21 months, located at $235^{\circ} \mathrm{E}$. While the two series at this location appear to represent a similar signal, defined by either an easterly flow $\left(225^{\circ} \mathrm{E}\right)$ or southerly flow $\left(235^{\circ} \mathrm{E}\right)$ peaking in 1997 and both decaying in time at the very low frequency, there are distinct differences that complicate the use of the series as shown in the wavelet decomposition and add uncertainties to using the more western location for predictions at the eastern location.

Quantifying how upstream current changes are reflected in the downstream current shows the similarity between the changes in the current. A time series from the upstream location, $x(t)$, is fit to the data at a downstream location at an offset $(o)$ in time, $y(t+o)$, determined from an examination of lagged correlation values and the location of the maxima. A "quality" ratio can then be calculated. A second order polynomial is used to fit the upstream data to the downstream data, resulting in an estimate of the downstream location's variability, $y_{e}(t+o)$. The difference between the estimate and the actual values, $D(t+o)=y_{e}(t+o)-y(t+o)$, is the error in the fit when trying to use upstream information to understand future downstream changes.

To understand how different location pairs relate in importance to one another, the error of the fit is normalized by the standard deviation of the true downstream signal: $y(t+o)$, resulting in a "quality of fit" estimate. In other words, if the error variance is the same or larger than the actual signal variance, then there is a large uncertainty in the estimate, especially if the "quality" values are greater than 1. A low value means that the error is lower than the signal's variance and then there is some possibility that the upstream signal may contribute to the downstream variability. Note that this is not attempting to produce a usable predictive equation. That would require a much more complex statistical analysis. Rather, it is only to illustrate when there is a measure of predictive skill in the upstream/downstream relationship.

Two examples were examined, using the data shown in Fig. 13: 1) zonal velocity at $47^{\circ} \mathrm{N}, 215^{\circ} \mathrm{E}$ (upstream) with meridional velocity at $47^{\circ} \mathrm{N}, 232^{\circ} \mathrm{E}$ (downstream) $(R=0.80)$ and 2) zonal velocity at $37^{\circ} \mathrm{N}, 235^{\circ} \mathrm{E}$ (upstream) with meridional velocity at $37^{\circ} \mathrm{N}, 235^{\circ} \mathrm{E}$ (downstream) $(R=0.54)$. Only the data after 2000 for the first pair is used because this is the significant portion of the time series at low frequencies. The first pair uses a temporal lag of 2 months. The second example uses a lag of 1.7 years over the full record.

The rms differences in the estimated or fitted series and the actual values for the two sets are 0.73 and $1.65 \mathrm{~cm} / \mathrm{s}$ average standard deviation of the error, $\left(S=\sqrt{\frac{1}{T} \sum_{t=t 0}^{T}(D * D)}\right)$, where $T$ is the length of the record and $t 0$ is the initial time. The calculated "quality" values are 0.68 and 0.90 (no units). Thus, relative to each other, only the first upstream/downstream pair $\left(47^{\circ} \mathrm{N}, 215^{\circ} \mathrm{E}\right.$ and $\left.47^{\circ} \mathrm{N}, 232^{\circ} \mathrm{E}\right)$ gives an indication that the upstream condition is influencing the downstream condition. The other two comparisons indicate that the error in using the upstream condition to predict the downstream condition is less certain, but still the error is less than the variability in the observed record at the downstream location.

\subsection{Potential ocean based indices}

The SSH anomaly signal of the Northeast Pacific was decomposed into 3 spectral bands, 3-9 months, 2-3 years and 4-6 years to show the relationships between the spatial and temporal changes of the signal's spectral energy bands. There is a complicated structure in time and space of the SSH variability and, thus, of the circulation of the Northeast Pacific Ocean. We also showed the difficulty of using broad atmospheric indices to understand many of the changes in the 
ocean and whether advection plays a significant role. Based on the information provided above, a set of ocean based indices can be defined that allows for the information about the signal's variability to be consolidated and clarified. The spectral decomposition suggests the SSH variability and the associated flow patterns might be represented by several SSH based indices: 1) an index representing the low frequency changes associated of the northern gyre (sub-region 6, see Sect. 3.3.4, 3.4.2), 2) an index representing region 2, near $52^{\circ} \mathrm{N}$, along the coast (see Sect. 3.4.1, 3.4.2), and 3) an index representing region four centered at $37^{\circ} \mathrm{N}, 235^{\circ} \mathrm{E}$ (area 4 , see Sect. 3.3.2, 3.4.2). Data from the winter period is used to develop the indices to be consistent with the atmospheric indices shown.

Correlations between the indices were computed to quantify the similarity between them. Correlations were also computed between the SSH indices and various atmospheric indices. The coastal index at $52^{\circ} \mathrm{N}$ is only highly correlated with the ENSO/MEI index (0.8) when 1998/1997 is included. Otherwise, the coastal indices as defined here are not highly significantly correlated to any of the atmospheric indices (maximum $R$ values are approximately $0.3-0.5$ ). The SSH northern gyre index (1) is not significantly correlated with either the PNA or ALPI index. While the correlation of the coastal SSH indices and their connection to ENSO processes is not new, especially when an extreme ENSO event is present in the time series, the SSH based indices can help to identify low frequency changes, other than ENSO, in the ocean that are particular to an area. The lack of significant correlations with the atmospheric indices indicate a need for ocean-only indices.

An example of how these indices can be used is shown by comparing the changes to estimates of fish catch in a particular area. In the previous section, it was shown how the information in the SSH signal upstream and downstream is related and this information may help with understanding changes in fish stock due to changes in circulation patterns and may contribute to projecting potential fish catch. In Fig. 14, annual estimates of fish catch (personal communication from the National Marine Fisheries Service, 2008) are shown as symbols overlaying the various examples of SSH indices. Similarities in trends can be observed between the various species and with the indices from the regions that may influence their catch size. Figure 14a, the gyre index, shows a strong correspondence with two species, salmon and rockfish, a gyre index relating to the more coastal catch of fish with a lag of 1 year. The fish data is based on yearly values, and 1 year is the smallest possible lag other than zero. The salmon catch anomalies show similarities in changes seen in the index with a 1 year lag, while the rockfish catch is similarly negatively related to the SSH index. The same correspondence is not seen with the rockfish catch and the local coastal index with no lag (Fig. 14b). In the coastal region, at $37^{\circ} \mathrm{N}$, prior to 2002 , there is a similarity in the rockfish catch with the SSH index connected with area 4 (with 1997
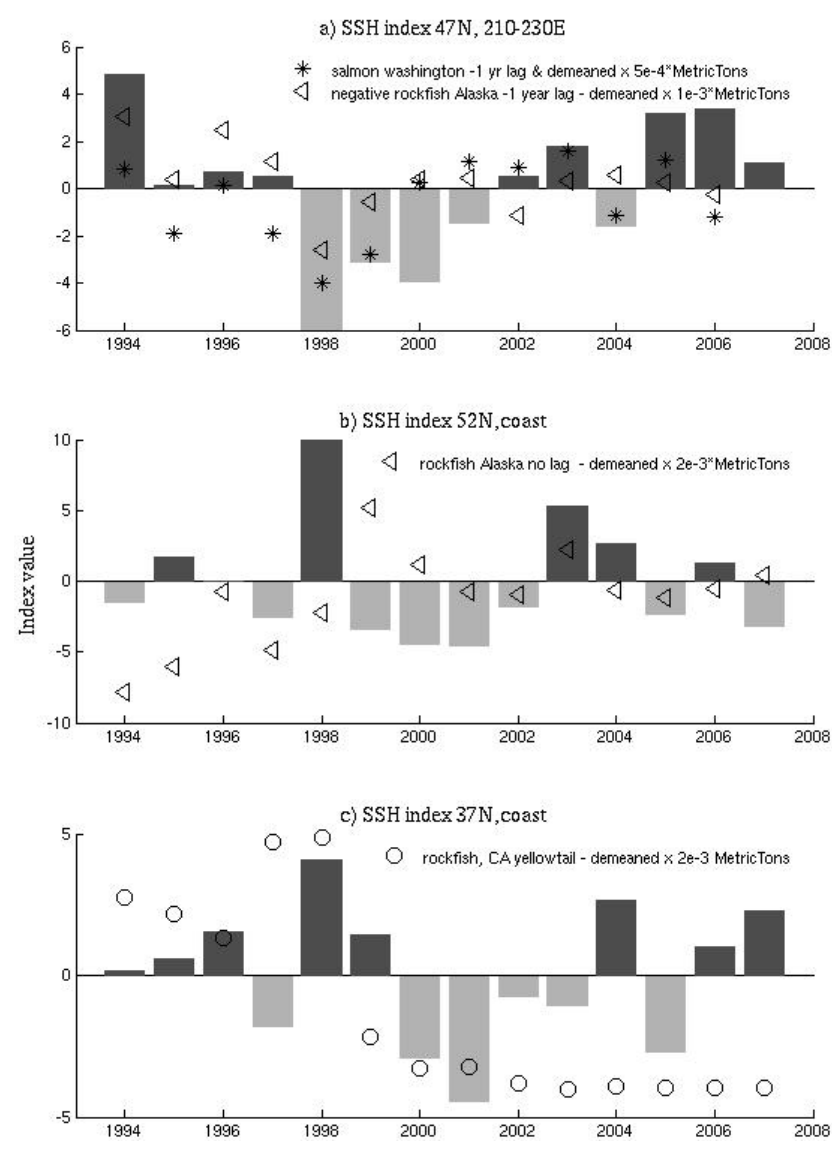

Fig. 14. A set of winter-time averaged indices based on SSH anomalies for regions of the Northeast Pacific Ocean. (a) Eastern subpolar gyre index, (b) Alaskan coastal index, and (c) California Current index (area 4). Fish species are denoted by the identified species in the legend. The fish catch data were obtained from http://www.st.nmfs.gov/st1/index.htm: personal communication from the National Marine Fisheries Service, 2008, Fisheries Statistics and Economics Division, Silver Spring, MD.

being an anomaly), but from 2002 and later, the catch is constant. This, most likely, is due to restrictions placed on the fisheries, rather than fish available to be caught. Understanding the relationships between such SSH based indices and the variability in fish populations will need to be further explored and is only shown here as an example of possible uses of such ocean based indices.

\section{Conclusions}

The goal of the analysis was to examine and explore the altimeter data set to understand how decomposing the height signal can help in determining ocean regions where the SSH anomaly signal can be used to monitor significant changes in circulation patterns and if such signals can be used to 
understand downstream changes. The analysis of a fifteen year time series of altimeter data in the Northeast Pacific through the use, primarily, of wavelets, shows that the SSH variability differs significantly across the larger region, resulting in different frequencies of variability dominating in different regions. The three bands of variability examined were a 3 to 9 month band, a 2 to 3 year band, and a 4 to 5 year band. The analysis identified three distinct indices that can be useful for monitoring changes in the Northeast Pacific: 1) $\left.47^{\circ} \mathrm{N}, 210-230^{\circ} \mathrm{E}, 2\right)$ a northern coastal area index, near $52^{\circ} \mathrm{N}$ (area 2) and 3) an index in the California Current region around $37^{\circ} \mathrm{N}$ (area 4).

The final conclusions are:

1. by decomposing the SSH anomaly into its frequency bands in time, the significant signals were determined for various areas and showing their significance in time. The decomposition showed that there are distinct broad areas of similar spectral energies and areas of dissimilarities. Based on this spectral decomposition, an example of the relationships between upstream and downstream circulation changes was given.

2. From the examination of the spectral characteristics of different regions, a set of three, distinct SSH indices are suggested, one for the northeast coastal area, one for the southeast area and one for the interior of the subpolar gyre area.

3. An SSH based index is not proposed for region 5 (25$45^{\circ} \mathrm{N}$, west of $230^{\circ} \mathrm{E}$ ) because the area is influenced by locally forced and chaotic events and is generally less energetic with the dominant signal difficult to determine.

The wavelet analysis has allowed for dominant signals in SSH to be identified as a function of time, along with spatially quantifying the regional significance of the signal within each band. In three areas, the indices show promise for monitoring changes in circulation which could be important for understanding connections between the physical and non-physical aspects of the ocean.

Acknowledgements. The author thanks Peter Challenor for advice and constructive suggestions on the paper. Two anonymous reviewers are also thanked for helpful comments, especially to improve the paper's clarity. Wavelet software was provided by C. Torrence and G. Compo, and is available at URL: http://atoc.colorado.edu/research/wavelets/.

Edited by: J. M. Huthnance

\section{References}

Barnston, A. G. and Livezey, R. E: Classification, seasonality and persistence of low-frequency atmospheric circulation patterns, Mon. Weather Rev., 115, 1083-1126, 1987.
Beamish, R. J., Neville, C. E., and Cass, A. J.: Production of Fraser River sockeye salmon (Oncorhynchus nerka) in relation to decadal-scale changes in the climate and the ocean, Can. J. Fish. Aquat. Sci., 54, 543-554, 1997.

Capotondi, A., Alexander, M. A., Deser, C., and Miller, A. J.: Lowfrequency pycnocline variability in the northeast Pacific, J. Phys. Oceanogr., 35, 1403-1420, 2005.

Chelton, D. B. and Davis, R. E.: Monthly mean sea-level variability along the west coast of North America, J. Phys. Ocean., 12, 757784, 1982.

Codiga, D. L. and Eriksen, C. C.: Observations of low-frequency circulation and amplified subinertial tidal currents at Cobb Seamount, J. Geophys. Res., 102, 22993-23007, 1997.

Cummins, P. F. and Lagerloef, G. S. E.: Low frequency pycnocline depth variability at the Station P in the northeast Pacific, J. Phys. Oceanogr., 32, 3207-3215, 2002.

Douglass, E., Roemmich, D., and Stammer, D.: Interannual variability in northeast Pacific circulation, J. Geophys. Res., 111, C04001, doi:10.1029/2005JC003015, 2006.

Ducet, N., Le Traon, P.-Y., and Reverdin, G.: Global high resolution mapping of ocean circulation from TOPEX/Poseidon and ERS-1 and -2, J. Geophys. Res., 105, 19477-19498, 2000.

Farge, M., Wavelet transforms and their applications to turbulence, Annu. Rev. Fluid Mech., 24, 395-457, 1992.

$\mathrm{Gu}, \mathrm{D}$. and Philander, G. H.: Secular changes of annual and interannual variability in the Tropics during the past century, J. Climate, 8, 864-876, 1995.

Haney, R., Hale, R., and Dietrich, D.: Offshore propagation of eddy kinetic energy in the California Current, J. Geophys. Res., 106, 11709-11717, 2001.

Kelly, K.A., Beardsley, R., Limeburner, R. C., Brink, K. H., Paduan, J. D., and Chereskin, T. K.: Variability of the near surface eddy kinetic energy in the California Current based on altimeter, drifter, and moored current data, J. Geophys. Res., 103, 1306713083, 1998.

Liu, P. C.: Wavelet spectrum analysis and ocean wind waves, Wavelets in Geophysics, edited by: Foufoula-Georgiou, E. and Kumar, P., Academic Press, 151-166, 1994.

Lluch-Belda, D., Lluch-Cota, D. B., and Lluch-Cota, S.: Scales of Interannual Variability in the California Current System: associated phyical mechanisms and ecological impacts, CalCOFI Rep., 44, 76-85, 2003.

Mantua, N. J., Hare, S. R. , Zhang, Y., Wallace, J. M., and Francis, R. C.: A Pacific Interdecadal Climate Oscillation with Impacts on Salmon Production, B. Am. Meteorol. Soc., 78, 1069-1979, 1997.

Meyers, S. D., Kelly, B. G., and O'Brien, J. J.: An introduction to wavelet analysis in oceanography and meteorology: With application to the dispersion of Yanai waves, Mon. Weather Rev., 21, 2858-2866, 1993.

Smith, W. H. F. and Sandwell, D. T.: Global seafloor topography from satellite altimetry and ship depth soundings, Science, 277, 195-196, 1996.

Strub, P. T. and James, C.: Altimeter-derived surface circulation in the large-scale NE Pacific Gyres. Part 1. seasonal variability, Deep-Sea Res. II, 53, 163-183, 2002a.

Strub, P. T. and James, C.: Altimeter-derived surface circulation in the large-scale NE Pacific Gyres. Part 2: 1997-1998 El Niño anomalies, Prog. Oceanogr., 53, 185-214, 2002b. 
Strub, P. T. and James, C.: The 1997-1998 oceanic El Niño signal along the southeast and northeast Pacific boundaries - an altimetric view, Prog. Oceanogr., 54, 439-458, 2002c.

Tanimoto, Y., Iwsaka, N., Hanawa, K. and Toba, Y.: Characteristic variations of sea surface temperature with multiple time scales in the North Pacific, J. Climate, 6, 1153-1160, doi:10.1175/15200442(1993)006, 1993.

Tokmakian, R. and McClean, J. L.: How realistic is the high frequency signal of a $0.1^{\circ}$ resolution ocean model?, J. Geophys. Res., 108, 3115, doi:10.1029/2002JC0014462003, 2003.
Torrence, C. and Compo, G. P.: A practical guide to wavelet analysis, B. Am. Meteorol. Soc., 79, 61-78, online available at: http://paos.colorado.edu/research/wavelets/bams_79_01_0061. pdf, 1998.

Wolter, K. and Timlin, M. S.: Monitoring ENSO in COADS with a seasonally adjusted principal component index. Proc. of the 17th Climate Diagnostics Workshop, Norman, OK, NOAA/N MC/CAC, NSSL, Oklahoma Clim. Survey, CIMMS and the School of Meteor., Univ. of Oklahoma, 52-57, 1993. 